\title{
The Similarities and Differences between Kunqu Zaju Opera and Zaju Chuanqi Opera
}

\author{
Yanhui Li \\ School of Art and Design \\ Huanghe Science and Technology College \\ Zhengzhou, China 450046
}

\begin{abstract}
It is well known that Zaju has undergone tremendous changes in many aspects in the middle period of Ming Dynasty due to the effect of Southern Opera and Chuanqi, and gradually was assimilated into Kunqu and Chuanqi. Similarly, Chuanqi was assimilated into Zaju in later period due to the effect of Zaju. They tend to be the same in many aspects, so it is difficult to distinguish. This article tries to study their similarities from their system (including four aspects, scale of script, use of tune system, arrangement and use of gong mode and work division of role), and to distinguish their differences from complicacy of internal structure and items of their roles.
\end{abstract}

Keywords-Zaju; Kunqu style; Chuanqi; Zaju Style; similarities; differences

\section{INTRODUCTION}

As a kind of operatic literary style, Zaju Opera developed to the peak in the Yuan Dynasty. Mr. Wang Guowei praised Zaju of Yuan Dynasty as "Masterpiece of A Generation" in his work of Chinese Opera History of Song and Yuan Dynasties, and he said "it is like the literature of Yuan Dynasty, so many playwrights can not increase any thing in it". Thus, ${ }^{1}$ it can be seen that Zaju of Yuan Dynasty can be considered as standard model to study Zaju system. For the study on the changes of Zaju system, it is inevitably to take Zaju System of Yuan Dynasty as reference object.

\section{FEAT URES OFZAJU SYSTEM}

As everyone knows that the basic structure of Zaju of Yuan Dynasty consists of four acts and one wedge. If an opera has four acts, it means that this opera is composed by four series of songs. Each series is composed of different tune names at same gong mode. Besides the four acts, the Zaju of Yuan Dynasty also has one wedge or two wedges in general. It is not as act with several series of songs that wedge is composed of one or two songs. And, songs in wedge are combined with the former act or the later act as one part in most cases. With relatively free position, the wedge can be both put before the first act and between acts. In addition, the singing of Zaju of Yuan Dynasty follows a rule of one lead singer. In other words, generally Zheng Dan

\footnotetext{
${ }^{1}$ Excerpted from Wang Guowei's Chinese Opera Hist ory of Song and
} Yuan Dynasties published by Shanghai Ancient Book Press, Version 1998 (chief female role) or Zheng Mo (chief male role) acts as the lead singer. The chief female or chief male role acting as main singer generally can play one major role in an opera, or can act several roles in each act. But, there must be only one person acting as main singer and singing to the end. The other roles do not sing and just speak in spoken parts. Even when the chief female role and the chief male role are in same act, only one of them sings and the other does not sing. Moreover, the paper also analyzes the use of tune and gong mode in Zaju of Yuan Dynasty. The Zaju of Yuan Dynasty belongs to the music system of northern opera, so it mainly uses the tune of northern opera. The Zaju of Yuan Dynasty mainly use the twelve gong mode in the music system of northern opera, which lists each name of tune into corresponding gong mode and use the structure system of "a series of tune names in the same category of gong mode", and strictly use the names of tune in same gong mode in a series of songs.

The above refers to the standard system of Zaju of Yuan Dynasty. Due to the limitations of the system of Zaju of Yuan Dynasty, not all Zaju of Yuan Dynasty are completely in line with such strict standard. In many works of Zaju of Yuan Dynasty, a lot of playwrights had made a wide variety of breakthrough and flexibility to break the strict and fixed mode.

As for the scale of script, some works even are extended into five acts or six acts. For example Ji Junxiang's The Orphan of Zhao has five acts besides one wedge. Zhang Shiqi's Saihuayue Qiuqianji has six acts according to Record of the Past Playwrights. Romance of the Western Chamber has twenty acts, but in fact it puts five acts in one opera. In this way, each opera still has four or five acts. Nevertheless, it only increases the number of acts and still follows the rule of four acts in one standard opera. As for the main singer, it is generally the supporting role to act as main singer in wedge. For example, the secondary male role acts as main singer in the wedge of Selling Rice in Chenzhou. In some scripts, there is an appearance that the chief male role and the chief female role take turns to act as main singer in the acts. In Zhang Sheng Boils Seas, the chief female role acts as longnv in the first and fourth act and as xiangu in second act, and the chief male role acts as an elder and sings in the third act. In some other scripts, the secondary role can also sing one or two songs. For example, at the end of the third act of 
Guan Hanqing's Butterfly Dream, Chou (buffoon) sings the two songs of Duanzhenghao and Gun xiuqiu. But after all, it is an exception and can not be considered as regular singing in Zaju Opera. And the exception never changes the rule of one main singer in the system of Zaju Opera. As Wang Guowei said, "they are just used to decorate the opera and impossible to break the rule of Zaju of Yuan Dynasty". 2 There is also antiphonal singing in one act of Zaju of Yuan Dynasty. But only there is only one case to testify it. In the fourth acts of first, fourth and fifth book of Romance of the Western Chamber, the main singer is Zhang Sheng, but Yingying and Matchmaker also sing several songs, which is very few and is not enough to be the representative of the system of Zaju of Yuan Dynasty. For the use of gong mode, it is a limitation to use only one gong mode in the Northern Zaju. In order to break this limitation, there appear some exceptions, such as "Jiegong" and "modulation". For example, the second act of Shi Junbao's Qujiangchi uses the song series of Yizhihua (nanlv) as well as the song of Shanjingma (shangdiao). In the fourth act of Huolangdan, the song series of Yizhihua (nanlv) is added with the Modulation of Huolanger. These examples show that it allows some flexibility under the strict range of gong mode. There are some changes in Zaju of Yuan Dynasty, but they are under the wide range of the general system of Zaju of Yuan Dynasty and do not exceed it.

With time past by, the system of Zaju also develops and changes. Due to the effect of Southern Opera and Chuanqi, it was basically broken that one northern opera has four acts and one act has a series of songs and one main singer after the middle period of Ming Dynasty in the spreading course. The Zaju of this time and after this time appeared different characteristics with Zaju of Yuan Dynasty and Ming Dynasty.

The scale of script: the scrip of Zaju may have a range of one act to ten acts or even above ten acts, which is not limited. For example, Xu Wei's Kuanggu Shiyuyang Sannong has one act; Wu Weiye's Tongtiantai has two acts; Qitingguan has three acts; Liang Scholar Not Yielding to Old Age has five acts; Xu Fuzuo's Yiwenqian has six acts; Wang Heng's Yulunpao has seven acts; Ye Xianzu's Bilian Xiufu has eight acts; Wuzhong Qingnv's Xiangsipu has nine acts; John Doe's Zhulin Xiaoji has eleven acts. In this period, the wedge is dispensable and is not as important as in Zaju of Yuan Dynasty.

Single Lead Singing and Application of Gong Mode: The Zaju after Mid-Ming Dynasty has changed a lot compared with Yuan Zaju and the Zaju in early Ming Dynasty in terms of this aspect. From the above mentioned, we can learn that examples of flexibility, such as alternative lead singing by Zhengdan or Zhengmo, and inserting one or two songs by secondary role, have been existing in the period of Yuan Zaju, with an illustration that this flexibility will not affect the overall characteristics of Single Lead Singing of Yuan Zaju. Therefore, although such similar circumstance has been existing since Mid-Ming Dynasty, we cannot take it as

${ }^{2}$ Excerpted from Wang Guowei's Chinese Opera History of Song and Yuan Dynasties published by Shanghai Ancient Book Press, Version 1998 the mark to differentiate it from the characteristics of Single Lead Singing of Yuan Zaju. However, the aforementioned are minority after all in Yuan Zaju, yet appear in large quantity since Mid-Ming Dynasty with the combined use of them. The book of Study on Dramas in the Late Ming and Early Qing Dynasties has described such circumstance in detail, and has listed the Sequel of the Romance of West Chamber by Zha Jizuo as an illustration. In this drama, the number of person singing in each play is changing with the scenario but not just one person, which is similar to the above mentioned circumstance of alternative lead singing by Zhengdan or Zhengmo in Yuan Zaju, yet with more complicated changes. The circumstance that the first play of this drama [Bei Xianlv] is sung by Ergongshi and [Bei Shangdiao] is sung by Xiaosheng is similar to inserting one or two songs by secondary role in Yuan Zaju, yet more complicated. And in the second play of this drama, the three modes of [Bei Zhonglv], [Bei Huangzhong] and [Bei Banshediao] are sung by Dan, which is similar to the skill of "Jiegong" used in Yuan Zaju. However, such flexibility rarely appear in Yuan Zaju but is used a lot in Zaju since the Mid-Ming Dynasty and is freely used in combination if necessary, which is a great progress compared with the previous Yuan Zaju. Besides, Zaju after Mid-Ming Dynasty has developed other changes in terms of Single Lead Singing. Singing to one another on the same stage has appeared in Zaju of this period, for instance, the characters of the third and fourth play of Zuixinfeng by Mao Wei are nearly divided with equal shares. Although such arrangement has appeared in the Romance of West Chamber of Yuan zaju, yet as the above mentioned, that is quite rare. However, it has been increasing gradually since the Mid-Ming Dynasty, therefore, this can be seen as a progress of Zaju in Single Lead Singing following the Mid-Ming Dynasty. Shangqu has been used a lot in Zaju after Mid-Ming Dynasty, and the character arrangement of Zuju in Late Ming and Early Qing Dynasties is absolutely consistent with the common conditions in Nanqu Chuanqi, namely one character can act as any role and sing any play with freedom to sing along or in chorus.

Application of Tunes: Application of divertimento in Zaju of this period tends to be liberalized. Inserting Nanqu into Beiqu or using Nanqu in the whole play has been existing, for example, Xiaoyaoyou by Wang Yinglin has inserted [Bei Ban Shediao] into Nanqu belonging to the condition of combination use of Nanqu and Beiqu. However, only the last play of Menghuanyuan by Zhou Rubi is Beiqu with the rest to be Nanqu. In addition, there has been such condition as assembling Nanqu with Beiqu, for instance, the forth play of Banbihan by Nanshan Yishi has used such form. There is one more thing that we should pay attention to is that the the so called Nan Zaju has appeared in this period, namely, the whole Zaju is written in Nanqu, e.g. Gaotangmeng, Yuanshanxi, and Luoshuibei etc. by Wang Daokun are all written in Nanqu. The plays, such as Qiannv Lihun, by Wang Jide are with the intention to advocate "Write a Play Using Nanci".

The above mentioned conditions are the developments in systems of Zaju after Mid-Ming Dynasty, and to some extent, 
it also reflects the significant influence to systematical reform of Zaju by Nan xi and Chuanqi.

\section{FEATURES OF CHUANQI SYSTEM}

Chuanqi is the dramatic literature form that corresponds to Zaju in Ming and Qing Dynasties. There have been various opinions about definition of the connotation of Chuanqi. Guo Yingde has pointed out in the Record of Chuanqi in Ming and Qing Dynasties that "Chuanqi is a long drama script (commonly 20-50 plays) compared to Zaju; and it has the characteristics of normalization of literature system and the metricalization of musical system. Therefore, Chuanqi is a long drama script with the characteristic of normalization of literature system and the metricalization of musical system in terms of its connotation. "3 In his opinion, as for Chuanqi script, the tones (whether Nanqu, Beiqu or the various tones of Nanqu) do not hold the dominant role, and most of the Chuanqi script can be sung by changing various tones, and this is a clear proof. Yet the Drama Overview by Qian Nanyang and the Collection of Classic Dramas by Zhuang Yifu are all regard Chuanqi as the script of Kun Tone System after the Mid-Ming Dynasty. He holds the opinion that in addition to the plays in the Record of Nanci are belonging to drama, yet the rest are belonging to Chuanqi on the basis of Record of Nanci by Xu Wei of Ming Dynasty. Although, there are disputes about definition of the connotation of Chuanqi, the Chuanqi with Kunshan Tone has taken the leading place in the field of drama after the MidMing Dynasty without doubt. Whether or not the tone has a place in the definition of connotation of Chuanqi, the Chuanqi with Kunshan Tone can be regarded as representative of Chuanqi without doubt. Therefore, while we are studying the system of Chuanqi, we can take the Chuanqi with Kunshan Tone as the main object naturally.

Scale of the Script: The system of Chuanqi with Kunshan Tone is finalized in the middle and late periods of Jiajing. The Chuanqi with Kunshan Tone is usually quite long with 20-50 plays. However, the length of it has been shortened gradually in the late period of developing Chuanqi with Kunshan Tone with some even have just more than 10 plays. Chuanqi has tended to be dramatized since the years of Jiaqing and it has developed into a convention that Chuanqi with 8-12 plays appear in large quantity, which is significantly different from the Nan Zaju that is gradually evolving toward Kunqu with a script having no less than four plays. One Chuanqi is usually divided into two volumes; the final of the first volume is called "Small Shousha", and the final of the second volume is called "Big Shousha". The structure of Chuanqi with Kunshan Tone is in set pattern. More often than not, the first play is "Fumo Opening Speech", namely the description of the author's intention and general idea of the whole drama by Fumo using one or two lyrics. The second and third play is "the Home of Sheng and Dan": the chief actor acted by Sheng comes to stage in the second play, and the chief actress acted by Dan comes to stage in the third play, with their self-introduction

${ }^{3}$ Excerpted from Records of Chuanqis in Ming and Qing Dynasties by Guo Yingde, Hebei Education Press, Version 1997 respectively by sing lyrics and speaking part of the play. Then "Guanmu Comes to Stage" unfolds the plot of the drama. Generally, each play has the poem of next play. Such normalized literature system has developed into the template for Chuanqi creating in later ages.

Single Lead Singing and Application of Gong Mode: the characteristic of singing system of Kunshan Opera Chuanqi is free and varieble, that is to say, the singing arrangements of singers have no necessary links with gong mode sang by them. But later because of being influenced by the singing system of northern opera Zaju, the singing system of late Kunshan Opera Chuanqi also appears the tendency of closing to Zaju. This tendency firstly appears in the sing of northern opera tune used by them. Most of them have one lead singer. It appears that the lead singer occasionally uses northern opera in Chuanqi opera. For example, the songs (northern yuediao) used in Resistance to Marriage, the fourteenth act in Liyu's Shenzhonglou are sang by Dan (female role). There is a situation that the lead singer independently uses a complete set of northern opera in chuanqi opera. For example, the set of [Gathering of Talented Guests] (northern shangdiao) of Yichen, the tenth act in Palace of Eternal Life is sung by Wai. Besides, it also appears that the lead singer sings northern opera in the combination of northern opera and southern opera. For example, the northern opera in combination of northern opera and southern opera in Serve as an Envoy Abroad, the 33th act in Liyu's Lianxiangban is sung by Sheng (male role). Later, in one opera of Kunshan Opera Chuanqi, even the southern opera not subordinate to the same gong mode are sung by one lead singer. It's almost the same with the singing modes of some Zaju after the middle Ming dynasty.

Application of tune system: Kunshan Opera belongs to southern opera from the source of tune. But in reality, after Kunshan Opera is reformed by some people such as Wei Liangfu, a large number of even complete sets of northern opera tunes are largely cited by Kunshan Opera. Thus appears the tendency of combination of the northern opera and southern opera. Some Chuanqi scripts occasionally cite several tune names of northern opera in a lot of tune names of southern operas, such as the sixth drama in Wu Weiye's Molingchun. Later, more and more tune names of southern opera enter southern opera. Gradually, a series of tune names in the same category of the whole northern opera are borrowed as the music structure of an opera. For example, Tanyi, the twelfth opera in Story of Wash Yarn, cites a whole set of northern opera, [Rouged Lips] (xianlv). Moreover, there are mixed uses of the southern and northern operas in Kunshan Opera Chuanqi. It means that in an opera, there are northern operas as well as southern operas in a set of song. The first half part is southern opera and the latter part is northern opera, or the first half part is northern opera and the latter part is southern opera. For this situation, we can find proofs in Palace of Eternal Life. Scold the Thief, the 28th opera in it uses the structural form that the first half part is northern opera and the latter part is southern opera, which is also a new development of latter Kunshan Opera in the application of music form. The structural form of combination of southern opera and northern opera also has 
new development in latter Kunshan Opera Chuanqi. Three operas in Palace of Eternal Life use comb ination of southern opera and northern opera. Xuge, the 19th opera, uses a set of northern opera [Zuihuayin] (huangzhong) and southern opera [Foreword to Thrust]; Jingbian, the 24th opera, uses a set of northern opera [White Butterfly] (zhonglv) and southern opera [Qiyanhui]; Mingzhui, the 27th opera, uses a set of northern opera [Xinshuiling] (shuangdiao) and southern opera [bubujiao].

\section{CONCLUSION}

In conclusion, after the middle Ming dynasty, Zaju and Chuanqi affect each other and have mutual accommodation, which lead to the fact that the Zaju after middle Ming dynasty appears the tendency of closing to Kunqu Opera while the latter Kunshan Opera Chuanqi appears the tendency of closing to Zaju. Zaju closing to Kunqu Opera and the Chuanqi closing to Zaju gradually converge with little differences. It is difficult to distinguish them on the scale of scripts, the use of tune system, the arrangement and use of gong mode and the work division of roles.

How to distinguish them and find the differences? We can start from the following two aspects. First of all, there is a paragraph of words in Lv Tiancheng's Qupin, saying, "Zaju describes the beginning and end of a thing, and the artistic conception is rapid; Chuanqi elaborates a pers on from beginning and to end and it has lasting appeal. If there is no Zaju, then who can bring Chuanqi? Only Chuanqi can show the fun of Zaju."(1) It is a unique style of him to use the scale of external system and complicity of internal structure as characteristics to distinguish Zaju and Chuanqi. Secondly, to distinguish the difference of Zaju closing to Kunqu Opera and Chuanqi closing to Zaju, we can refer to the names of dramatic roles. In general, the roles of Zaju have three kinds: the lead roles, Zheng Mo (chief male role) and Zheng Dan (chief fe male role), belong to the first kind; in Mo Dan, roles that don't sing such as Chong Mo (secondary male role), Wai Mo, Xiao Mo and Wai Dan belong to the second kind; the third kind does not include Mo (middle-aged male role) and Dan(female role) but Jing (painted-face role) and Chou (buffoon), who don't sing. The whole system of roles in Kunshan Opera Chuanqi is the performing system that focuses on "Twenty Roles in Jianghu". Mainly include: Fo Mo, Lao Sheng, Zheng Sheng, Lao Wai, Da Mian, Xiao Chou, San Mian, Lao Dan, Zheng Dan, Xiao Dan, Tie Dan and Za. From this we can distinguish Zaju closing to Kunqu Opera and Chuanqi closing to Zaju from different names of roles in Zaju and Chuanqi. But in the works of Zaju Opera in late Ming and early Qing dynasty, some male roles aren't called "Mo" but "Sheng", such as Meng Chengshun's A Charming Face among Peach Blossoms. So using this method to distinguish the difference between them isn't absolutely accurate. It still needs to combine different characteristics of systems and contents of them and make overall investigation to accurately distinguish them.

\section{REFERENCES}

[1] Chinese Opera History, Zhang Geng and Guo Hancheng as chief editors, Chinese Opera Press, 1980

[2] Study on Dramas in the Late Ming and Early Qing Dynasties, Sun Shulei, Social Sciences Academic Press, 2007 Study on Dramas in the Late Ming and Early Qing Dynasties

[3] Chinese Opera History of Song and Yuan Dynasties, Wang Guowei, Shanghai Ancient Books Publishing House, 1998

[4] Some Thoughts Concerning Guqu, Overview of Chinese Opera, Wu Mei, Shanghai Ancient Books Publishing House, 1998

[5] Collection of Ming and Qing Chuanqi, Guo Yingde, Hebei Education Press, 1997 